\title{
A SURVEY OF LICENSED TREE EXPERTS IN MARYLAND
}

\author{
by Michael F. Galvin' and Peter J. Becker ${ }^{2}$
}

\begin{abstract}
In Maryland, persons engaged in the work of the treatment and care of trees for compensation must be licensed by the Department of Natural Resources. The Department of Natural Resources-Forest Service, the MidAtlantic Chapter of the International Society of Arboriculture, the Maryland Arborist Association, and the Maryland Community Forest Council cosponsored a survey of Licensed Tree Experts (LTEs). The survey's purposes were to estimate the total number of jobs and gross dollar revenue that the arboricultural industry provides to the state of Maryland; to identify the tree care industry as a constituency in the business community; to identify training resources and trade affiliations most used by LTEs; to identify business type, geographic concentration, and client type; and to provide input into agency regulations affecting the industry. It is estimated that the tree care industry in Maryland employs 2,841 individuals and generates more than $\$ 134.5$ million in annual gross revenue.
\end{abstract}

The state of Maryland requires all persons engaged in the business of the treatment and care of trees for compensation to be licensed by the Maryland Department of Natural Resources (DNR) (State of Maryland Annotated Code, Title 5). Those strictly engaged in the business of tree removal are not required to be licensed, because removal does not fall under the definition of "care." Licensed Tree Experts (LTEs) are required to meet criteria to be eligible to take the LTE test. Upon passing the test, individuals must annually pay a renewal fee and provide the Maryland DNR with valid proof of current insurance. Toward the end of each calendar year, renewal notices are sent to all LTEs. The Maryland DNR historically has gathered a good deal of information related to the forest products industry in the state. Similar information for the arboriculture/urban forestry industries has never been available.

Contacts with the National Arborist Association (NAA), the Maryland Arborist Association (MAA), the International Society of Arboriculture (ISA), and the University of Maryland Cooperative Extension Service revealed that no report or data concerning the information described exist- ed. In early 1996, the authors began the process of deciding how best to obtain the desired information.

A survey was generated and inserted as a supplement to the annual LTE license renewal package. Participants were requested to return only 1 survey per firm. At the time of survey generation, 302 firms were listed; this number dropped to 278 by the actual survey period.

Participation was on a voluntary basis. Submission was made with the Tree Expert license renewal. No attempt was made to relate a particular survey to a particular firm.

\section{Method}

The Maryland DNR provided comments and committed to support the project by way of staff hours and inserting the surveys into the renewal packages. The survey was subsequently submitted to the Mid-Atlantic Chapter of ISA (MAC-ISA), the Maryland Community Forest Council (MCFC), and MAA for dissemination to and comment from their organizations. All comments were compiled into a revised document and sent to cosponsors for approval, which was obtained by the end of September 1996.

All questions were formatted to be easily analyzed as data, that is, true/false or numeric formats. The survey was broken down into 8 primary sections, as noted in Table 1.

The total number of LTEs was obtained from Maryland DNR headquarters, and the appropriate number of surveys were generated and folded. The surveys were inserted into the annual renewal notices and mailed in mid-December 1996.

Formulas were created by which the gross revenue reported could be multiplied by the factors created in the percentage fields to obtain dollar values for three categories: client type, work type, and geographic area. The three categories were 
Table 1. LTE survey question category and data format.

\begin{tabular}{|c|c|}
\hline Category & Question: Format \\
\hline Affiliations & $\begin{array}{l}\text { Member: T/F } \\
\text { How many: Number }\end{array}$ \\
\hline Credentials & $\begin{array}{l}\text { Credential: T/F } \\
\text { Advertise credential: T/F } \\
\text { How many: Number }\end{array}$ \\
\hline Training & $\begin{array}{l}\text { T/F } \\
\text { Other: Fill In }\end{array}$ \\
\hline Employment & Number(s) \\
\hline Revenue & Number(s), Percentages \\
\hline $\begin{array}{l}\text { Work Type/ } \\
\text { Geographic Distribution }\end{array}$ & Percentages \\
\hline MD Tree Expert Law & $\begin{array}{l}\text { Rate on scale of } 1-5 \\
\text { Comments }\end{array}$ \\
\hline $\begin{array}{l}\text { MD Roadside Tree Law } \\
\text { and Regulations }\end{array}$ & $\begin{array}{l}\text { Rate on scale of } 1-5 \\
\text { Comments }\end{array}$ \\
\hline
\end{tabular}

tracked separately; each was supposed to add up to the same amount. However, because some participants reported client type but not geographic activity, the resulting geographic activity factor was 0 , causing some disparity in the totals. To help alleviate this, any revenue generated with no geographic association was tracked as "Other" and incorporated into totals for locations other than Maryland, Virginia, and Washington, D.C.

Two-hundred seventy-eight firms were listed at the time of analysis. One-hundred forty-nine surveys $(53 \%)$ were returned. Because the survey was self-selecting, 149 responses were not obtained to each question. Some participants chose to respond only to certain questions. This likely impacted the correlation analysis significantly.

To estimate the total number of employees and revenue generated, an attempt was made to develop a model to categorize firms by number of employees and revenue generated. Factors for estimating total employees and total revenue generated by each group were determined by dividing the estimated number of firms per firm size by the number of firms reporting to obtain a multiplier for each firm size as follows: small firms-3.3818; medium firms-2.4642; and large firms-1.00 (Table 2).

Gross revenue generated per firm size was estimated by multiplying the estimated revenue
Table 2. Maryland tree care firm descriptive models-employees.

\begin{tabular}{llll}
$\begin{array}{l}\text { Firm } \\
\text { size }\end{array}$ & $\begin{array}{c}\% \text { of } \\
\text { firms }\end{array}$ & $\begin{array}{l}\text { \# employees } \\
\text { per firm size }\end{array}$ & $\begin{array}{c}\% \text { of total employees } \\
\text { per firm size }\end{array}$ \\
\hline Small & $67 \%$ & 5 or fewer & $19.6 \%$ \\
Medium & $25 \%$ & $6-13$ & $22.2 \%$ \\
Large & $8 \%$ & 14 or more & $58.1 \%$ \\
\hline
\end{tabular}

Table 3. Maryland tree care firm descriptive models-revenue.

\begin{tabular}{llll} 
Firm & $\begin{array}{l}\text { Avg. gross } \\
\text { revenue } \\
\text { size }\end{array}$ & $\begin{array}{l}\text { Avg. revenue } \\
\text { generated } \\
\text { per employee }\end{array}$ & $\begin{array}{l}\% \text { of total } \\
\text { revenue per } \\
\text { firm size }\end{array}$ \\
\hline Small & $\$ 174,732$ & $\$ 58,244$ & $24.1 \%$ \\
Medium & $\$ 466,964$ & $\$ 51,885$ & $23.9 \%$ \\
Large & $\$ 3,046,739$ & $\$ 42,912$ & $51.9 \%$ \\
\hline
\end{tabular}

per employee for each firm size times the mean number of employees per firm size times the number of firms per firm size, as noted in Table 3. This was checked against, and found to be equal to, the average gross revenue per firm size times the number of firms per firm size.

\section{Survey Results and Discussion}

Affiliations. Affiliations with 4 professional organizations were evaluated: the International Society of Arboriculture (ISA Membership Application), the Maryland Arborist Association (MAA Membership Invitation ), the National Arborist Association (NAA Active Member Application), and the Maryland Nurserymen's Association (MNA Membership Application). The results are shown in Figure 1. MAA enjoys the highest membership among LTEs, with ISA a close second. Member individuals are also likely to seek training from their respective organizations. There were almost as many firms with NAA members as with MAA or ISA members, but NAA had far fewer individual members. While this could be considered to be due to the existence of MAA, that is unlikely, because firms with MAA members were likely to have NAA members also; members do not appear to view the organizations as mutually exclusive. While MAA members work in industry, government, and research, etc., NAA membership is limited to practicing commercial arborists, such as LTEs, and is usually held by the 


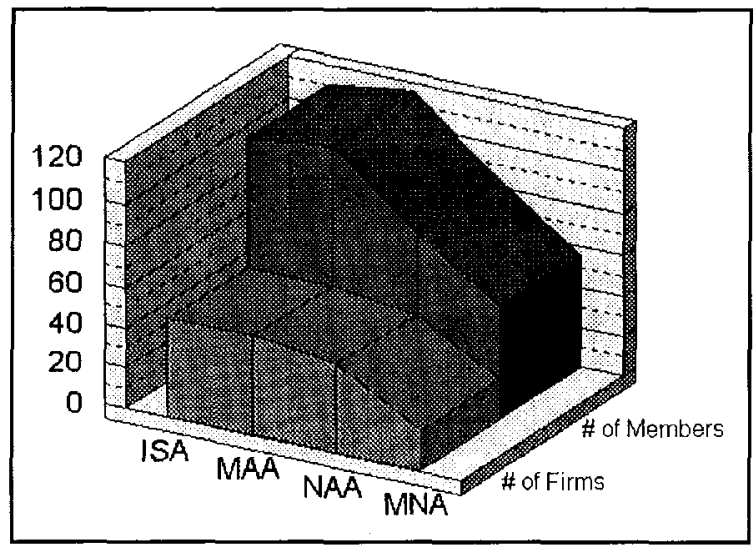

Figure 1. Affiliations-professional organization memberships.

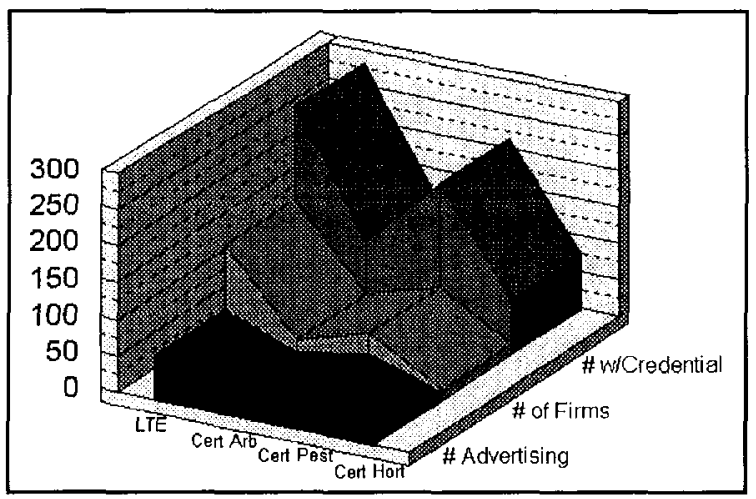

Figure 2. Credentials-licenses and certification.

principal(s) in a firm. While MNA had the lowest membership percentage among LTEs, it had the highest number of members per firm and was the only affiliation to be correlated to gross revenue and employment, making it a desirable affiliation for LTE firms and their clients.

Credentials. Four professional credentials were discussed: the Tree Expert License from the Maryland DNR (State of Maryland Annotated Code), the Certified Arborist credential from International Society of Arboriculture (ISA Certified Arborist Program brochure), the Certified Pesticide Applicator (CPA) license from the Maryland Department of Agriculture (State of Maryland, Department of Agriculture, Code of Maryland Regulations) and the Certified Professional Horticulturist $(\mathrm{CPH})$ credential from the Maryland Nurserymen's Association (MNA Vol- untary Certification Program brochure). The results are shown in Figure 2.

While the LTE credential was found to be most prevalent among firms and individuals, it was held by the smallest number of individuals per firm. From the responses to "Maryland Tree Expert Law" questions, it would appear that the credential is highly valued by the industry. In light of this, the reluctance to license more people per firm is not understood. It is recommended that the Maryland DNR advocate the benefits of the LTE law to the industry and work towards enhancing industry esteem of the program.

Firms with more LTEs are likely to have more Certified Arborists. This points to an already expressed industry desire to consider ISA certification as "equivalent education" under 5-418(a)(3) of the Tree Expert Licensing Law. This programmatic change is recommended. It is also recommended that the LTE program adopt a continuing education requirement similar to those required for Certified Arborists or Certified Pesticide Applicators. No such requirement currently exists.

Almost half of all firms participating reported having CPAs on staff, with $76 \%$ as many CPAs as LTEs practicing among firms. Spraying is a major component of the fertilization, Integrated Pest Management (IPM), and insect and disease program components discussed in the "Work Type" section; revenue from these activities accounts for almost $22 \%$ of all revenue-more than was reported for tree removal. This is another positive sign that customers are seeking care and maintenance options more often than simply requesting removal. Many companies involved in grounds maintenance and landscaping require a considerable amount of spraying, which may account for the correlation between the number of CPAs and the number of CPHs per firm.

Those possessing the MNA CPH credential value it. The companies surveyed hire more individuals per firm with that credential than with any of the other credentials listed. Participation in this program may allow arborists opportunities to work in some markets and situations that they had not previously, creating new business opportunities.

Training. Participants were asked to indicate whether or not they train with the following orga- 
nizations: the Maryland DNR, ISA, MAA, and MNA; more than one of these organizations could be selected. They were also provided a choice titled "Other," which could be filled in with the name of any other organization. The Maryland DNR, ISA, and MAA were listed in almost equal amounts as primary sources for training-approximately $25 \%$ each; MNA, NAA, and "Other" were also reported in virtually equal amounts-about $34 \%$ of the level as the 3 primary sources, or about $8 \%$ of the total.

Members of ISA, MAA, and MNA are fairly likely to seek training with their parent organization, while individuals and firms with a variety of affiliations and credentials seek training from DNR and NAA.

Employment. Participants were asked to provide the number of field employees; the number of administrative employees; and the number of total employees. Using the reported percentages of $83.22 \%$ field employees and $16.52 \%$ administrative employees and the tree care firm models, total statewide employment among the 278 firms is estimated at 2,841 employees, with 2,364 being field personnel, and 477 being administrative personnel.

Although large firms (14 or more employees) represent only $8 \%$ of all firms, they are thought to provide $58 \%$ of employment in the industry. Medium-sized firms (6 to 13 employees), while representing $25 \%$ of firms, provided $22.2 \%$ of jobs; small firms (5 or fewer employees), representing $67 \%$ of firms, supplied $19.6 \%$ of industry jobs.

The number of employees was, as expected, related to revenue generated. Removal was the work activity most correlated to the number of employees; pruning was the least.

Revenue. Participants were asked to provide total gross annual revenue, then provide percentages of business with utility, government, and business/residential clients. The total was then multiplied by the percentages to obtain dollar amounts for each client type for each entry; these totals were added to obtain dollar amounts for each client type. $\$ 93,760,300$ in total revenue was reported. Total annual gross revenue is estimated at $\$ 134,795,823$.

Revenue from utility clients represented $4.2 \%$ of all revenues, with $\$ 3.75$ million reported and
$\$ 5.66$ million estimated. Government client revenue totaled $\$ 14,280,590$, with $\$ 21,567,331$ estimated, or $16 \%$ of all revenue. Business and residential revenue comprised $79.8 \%$ of all revenue, with $\$ 71,239,060$ reported and $\$ 107,567,066$ estimated. Total statewide revenue distribution follows the suburban demographic distribution patterns, with the majority of revenue concentrated in the most affluent suburbs of the major metropolitan areas. With utility deregulation and outsourcing, government downsizing and outsourcing, and greater environmental aesthetic concerns expressed by homeowners and businesses, all of these categories show growth opportunities. Only $91 \%$ of the LTEs licensed in 1996 are practicing in 1997. It is not known whether this is due to market reductions or to greater market shares being obtained by well-performing firms.

Although large firms (14 or more employees) represented only $8 \%$ of all firms, they are thought to generate $51.9 \%$ of all revenue. Medium-sized firms ( 6 to 13 employees), while representing $25 \%$ of firms, provided $23.9 \%$ of all revenue; small firms (5 or fewer employees), representing $67 \%$ of firms, generated $24.1 \%$ of all revenue.

Small firms generated an average of $12 \%$ more mean dollars per employee $(\$ 58,244)$ per firm than medium-sized firms $(\$ 51,885)$ and $36 \%$ more per employee than large firms $(\$ 42,912)$. The reasons for the decrease in revenue generated per employee as firm size increases are not known. They may have to do with fixed overheads for equipment, training, regulatory compliance, administration, employee benefits, and other costs associated with larger firms.

Removal revenue was the work activity most closely linked to total revenue; pruning was the least so. Revenue generated from government clients was correlated to removal revenue more than any other work area; pruning was the least related work activity. Business and residential client revenue was correlated most closely to spray activities (insect and disease management, IPM, and fertilization), followed by removal, landscaping, and, finally, pruning.

Work type. Participants were requested to provide percentages of their total work volume represented by the following categories: pruning, 
Table 4. Revenue amounts and percentages by work type.

\begin{tabular}{llll}
\hline $\begin{array}{l}\text { Work } \\
\text { type }\end{array}$ & $\begin{array}{l}\text { Amount } \\
\text { reported }\end{array}$ & $\begin{array}{l}\text { Amount } \\
\text { estimated }\end{array}$ & $\%$ of total \\
\hline Pruning & $\$ 29,131,250$ & $\$ 43,431,214$ & $32.22 \%$ \\
Landscaping & $\$ 23,688,650$ & $\$ 35,289,546$ & $26,18 \%$ \\
Removal & $\$ 17,878,550$ & $\$ 26,662,613$ & $19.78 \%$ \\
Fertilization & $\$ 7,241,950$ & $\$ 10,797,145$ & $8.01 \%$ \\
Insect/Disease & $\$ 6,283,350$ & $\$ 9,368,309$ & $6.95 \%$ \\
IPM & $\$ 6,204,200$ & $\$ 9,246,993$ & $6.86 \%$ \\
\hline
\end{tabular}

removal, fertilization, landscaping/planting, insect and disease management (conventional/spraying), and IPM. These percentages were converted to factors and multiplied by the total gross revenue to obtain revenue amounts for each activity type. Revenue totals for work types are listed in Table 4.

Because pruning generated the most revenue, it was the activity least correlated to client type, geographic area, or work type, and it was the least dependent on other variables. Pruning generated an estimated $\$ 43,431,214$, accounting for $32.22 \%$ of gross revenue-more than $61 \%$ as much as removals $(\$ 26,662,613)$. We were pleased to see that maintenance and enhancement activities accounted for over $80 \%$ of revenues; less than $20 \%$ was spent for removal. This news is tempered by the fact that, as noted earlier, one does not have to be licensed in Maryland to perform removals. A large number of firms performing only removals would not be accounted for in this survey.

IPM totals were surprisingly high given that the services represented are relatively new. The amount spent on IPM was reported to be identical to that of conventional spray programs. It is likely that some crossover in reporting of these functions occurred; some participants made comments to the effect that they did not distinguish between the two.
If all of the spray program items (IPM, fertilization, and insect and disease management) were combined, they would account for $21.82 \%$ of all revenue reported, which would be greater than revenues reported for tree removal. As noted previously, $48 \%$ of firms reported CPAs on staff.

Geographic distribution. Participants were requested to assign percentages of work volume to Maryland counties, to the city of Baltimore, to Virginia, to Washington D.C., or to "Other." The percentages provided were multiplied by the values provided under gross annual revenue. These data were entered in a database in ArcView 3.0 to generate a geographic depiction of markets as shown in Figure 3. As can be seen, the highest activity levels are along the Baltimore/Annapolis/Washington, D.C. corridor, and progressively lessen away from the urban core.

The Maryland Licensed Tree Expert Law. When participants were asked if this credential is worth attaining, the mean response was the highest for any of the 8 regulatory program questions asked on the survey. It was also rated as beneficial to commercial tree care and attainable for employees who needed to possess it. It should be noted that the Maryland Arborist Association originally formed in order to promote this law; the law was passed in 1957.

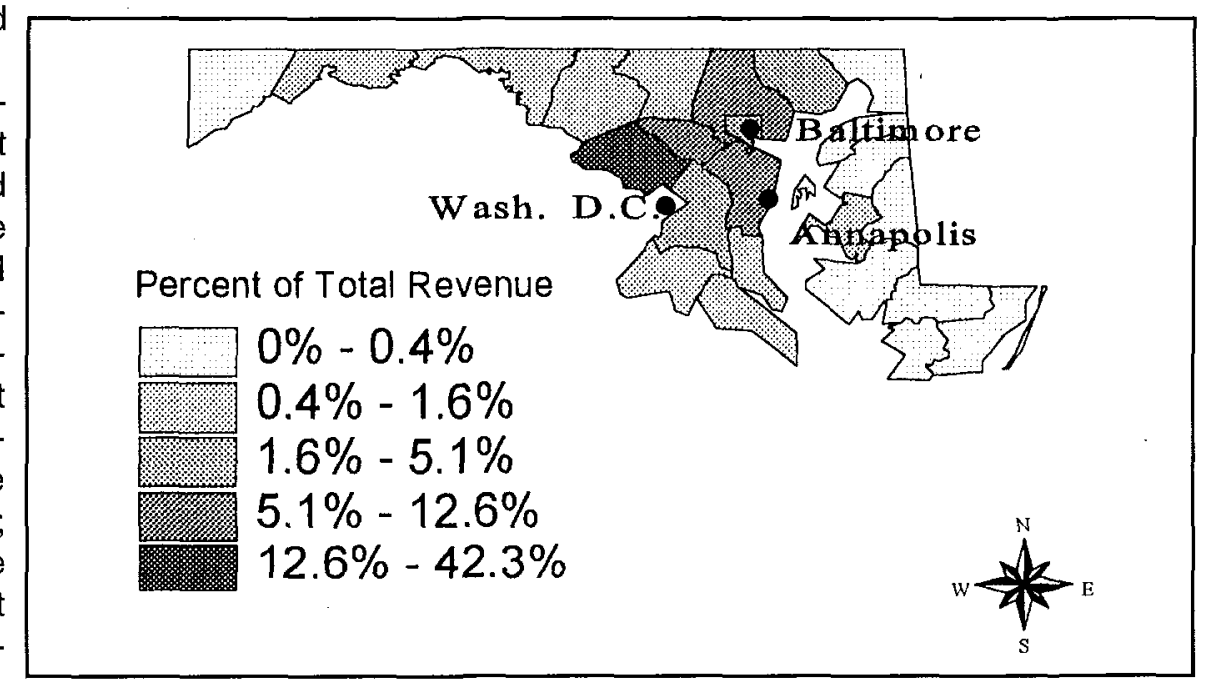

Figure 3. LTE revenue distribution by geographic region. 
The survey question regarding enforcement of the Tree Expert Law had the lowest mean response of any of the 8 regulatory program questions and had the lowest median response of any of the 4 LTE questions. From the data and the comments submitted, it is obvious that participants feel strongly that enforcement is the weakest component of the LTE program.

Recommended actions include improvement of enforcement, continuation of agency involvement with professional organizations, institution of a continuing education/recertification component for LTEs, and regulatory revisions to include removal in the definition of "tree care" under Natural Resources Article 5-418 (State of Maryland, Annotated Code).

The Maryland Roadside Tree Law and Regulations. The Roadside Tree Law (RST) places trees in all public road rights-of-way in Maryland under DNR's jurisdiction (State of Maryland DNR, Code of Regulations). Those responding indicated support for the clarity of the regulations, supported the arboricultural soundness of the RST regulations, and agreed that the law is beneficial to the industry. As with the LTE program, the enforcement component of the RST program was ranked weakest by participants, although not as poorly as in the LTE section.

Recommended actions include increasing industry awareness of the law through communication with trade associations and their publications, and institution of continuing education requirements for LTEs.

\section{Summary}

Commercial arboriculture contributes significantly to the Maryland economy and employment base. Both revenue and employment are concentrated most heavily along the Baltimore/Annapolis/ Washington, D.C. corridor. The only affiliations and credentials that showed a meaningful correlation to gross revenue were the Maryland Nurserymen's Association membership and their Certified Professional Horticulturist credential. This effect may be in part due to the low numbers of firms and individuals involved, compared with other affiliations and credentials. While regulatory mechanisms administered by the Depart- ment of Natural Resources are viewed as beneficial by the industry, their worth is questionable without adequate enforcement.

\section{Literature Cited}

International Society of Arboriculture. 1997. Membership Application. Arborist News. 6:4.

International Society of Arboriculture. Certified Arborist Program (brochure). International Society of Arboriculture. Savoy, IL. $12 \mathrm{pp}$.

Maryland Arborist Association. Membership Invitation (brochure). Maryland Arborist Association. Wheaton, MD USA. $1 \mathrm{p}$.

Maryland Nurserymen's Association. Membership Application. Maryland Nurserymen's Association, Inc. Baltimore, MD. 1 p.

Maryland Nurserymen's Association. Voluntary Certification Program For Professional Horticulturists (brochure). Maryland Nurserymen's Association. Baltimore, MD. 1 p.

National Arborist Association. Active Member Application (brochure). National Arborist Association. Amherst, NH. 1 p.

State of Maryland. Annotated Code of Maryland. Title 5. Forests and Parks. Subtitle 4. Trees and Nurseries. Part III. Tree Experts. Sec. 5-417. Office of State Documents. Annapolis, MD.

State of Maryland. Annotated Code of Maryland. Title 5. Forests and Parks. Subtitle 4. Trees and Nurseries. Part III. Tree Experts. Sec. 5-417 through 5-423.; Sec. 5-1301 and 5-1302. Office of State Documents. Annapolis, MD.

State of Maryland, Department of Agriculture. Code of Maryland Regulations. Regulations Pertaining To The Pesticide Applicators Law. Title 15. Department of Agriculture. Subtitle 05. Pesticide Use Control. Chapter 01. Use and Sale of Pesticides, Certification of Pesticide Applicators and Pest Control Consultants, and Licensing of Pesticide Businesses. Office of State Documents. Annapolis, MD.

State of Maryland, Department of Natural Resources. Code of Maryland Regulations. Title 08. Department of Natural Resources. Subtitle 07. Forest and Parks. Chapter 02. Roadside Tree Care. Office of State Documents. Annapolis, MD USA. 
Acknowledgments. Support for this project came from the Maryland Department of Natural Resources, the Maryland Arborist Association, the Mid-Atlantic Chapter of the International Society of Arboriculture, the Maryland Community Forest Council, the F.A. Bartlett Tree Expert Company, and the many Maryland Licensed Tree Experts that participated in the survey. The assistance of all those mentioned was greatly appreciated.

Urban Forester

Maryland Department of Natural ResourcesForest Service

Tawes State Office Building, E-1

580 Taylor Avenue

Annapolis, MD 21401

${ }^{2}$ Vice President/Division Manager

F.A. Bartlett Tree Expert Company 2950-C Industrial Park Drive

Finksburg, MD 21048 